\title{
GESTÃO DE OPERAÇÕES E SERVIÇOS
}

A gestão de operações e serviços compreende um conjunto de atividades que transformam insumos (recursos) em bens e serviços (produtos) demandados pelos consumidores. Tais atividades ocorrem em todas as organizações. Os seguintes aspectos são envolvidos: a) a definição dos objetivos estratégicos; b) as ferramentas técnicas ou quantitativas empregadas e c) o gerenciamento dos recursos humanos. No ambiente atual, a gestão de opera- ções e serviços interage com outras funções como engenharia, marketing e finanças, auxiliando a organização no atendimento de seus objetivos estratégicos. Na lista que se segue, elaborada pelo professor Roberto Giro Moori, do curso de Mestrado em Administração de Empresas da Universidade Presbiteriana Mackenzie e Doutor em Engenharia de Produção pela Escola Politécnica da USP, são apresentadas obras essenciais sobre o tema.

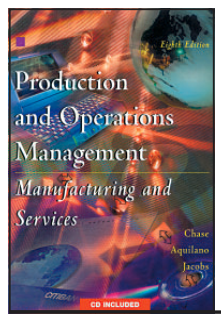

PRODUCTION AND OPERATIONS MANAGEMENT: manufacturing and services Richard B. Chase, Nicholas J. Aquilano and F. Robert Jacobs. Boston : Irwin / McGraw-Hill, $8^{\text {th }}$ edition, 1998. $889 \mathrm{p}$.

Esta obra abrange temas de grande importância para o mundo empresarial. Tópicos que antes eram tratados isoladamente, neste livro são abordados de forma integrada à gestão da produção e operações. A obra enfatiza a importância da gestão de pessoas e as tecnologias de informação como recursos importantes para a criação de riqueza e a prestação de serviços de qualidade.

OPERATIONS MANAGEMENT: providing value in goods and services James B. Dilworth. Florida : The Dryden Press, $3^{\text {th }}$ edition, 2000. 762 p.

O autor descreve de forma precisa os conceitos mais importantes da administração da produção e operações. O gerenciamento da cadeia de suprimentos (supply chain management), como meio de adicionar valor para os consumidores, é um dos assuntos centrais. Temas como localização, layout, gestão da qualidade, programação e sequenciamento são tratados com rigor matemático, de modo claro e objetivo.
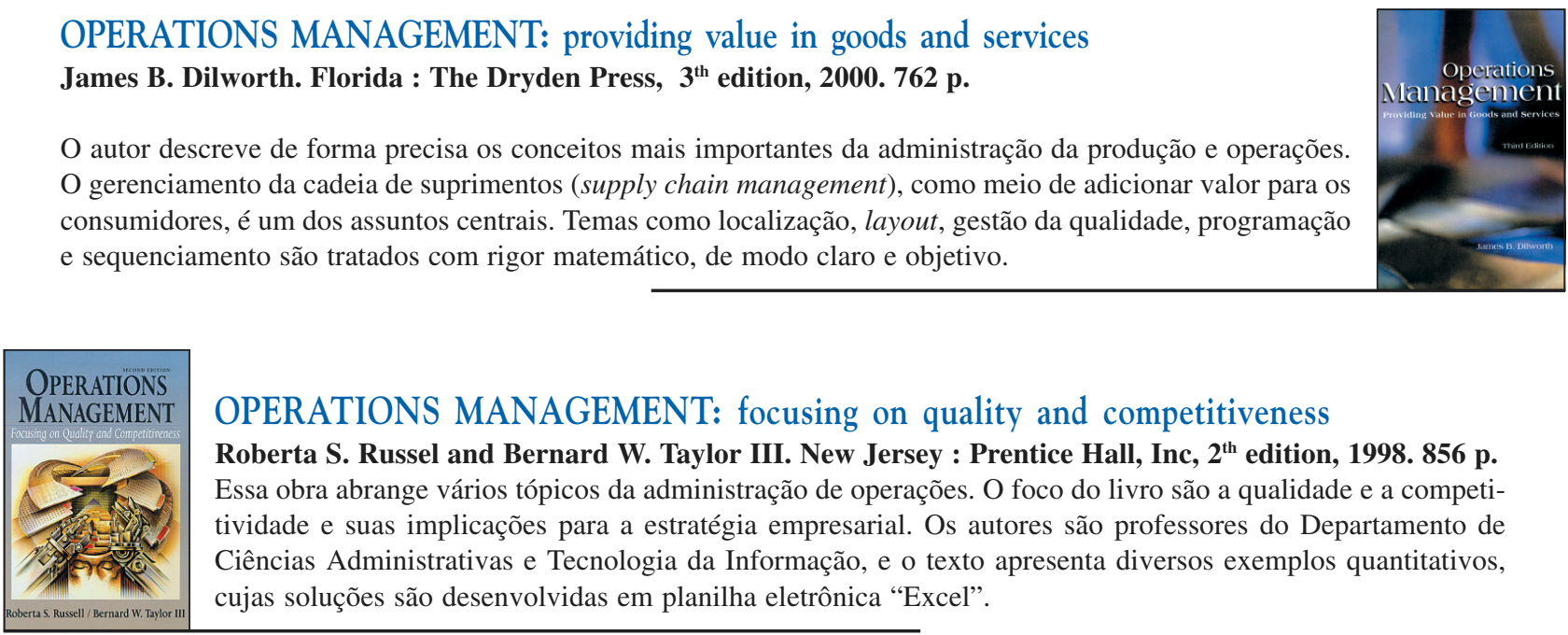

OPERATIONS MANAGEMENT: focusing on quality and competitiveness

Roberta S. Russel and Bernard W. Taylor III. New Jersey : Prentice Hall, Inc, $2^{\text {th }}$ edition, 1998. 856 p. Essa obra abrange vários tópicos da administração de operações. O foco do livro são a qualidade e a competitividade e suas implicações para a estratégia empresarial. Os autores são professores do Departamento de Ciências Administrativas e Tecnologia da Informação, e o texto apresenta diversos exemplos quantitativos, cujas soluções são desenvolvidas em planilha eletrônica "Excel".

\section{ADMINISTRAÇÃO DE OPERAÇÕES - Bens e Serviços} Jay Heizer e Barry Render. Rio de Janeiro : LTC - Livros Técnicos e Científicos Editora S/A, $5^{\text {a }}$. edição, 2001. 647 p.

Essa obra apresenta uma visão do estado da arte das atividades de gestão de operações. Inclui uma combinação de tópicos de contabilidade, engenharia industrial, gerenciamento, pesquisa operacional e estatística. Os autores preocuparam-se com os leitores que não pertencem à área, ajudando-os a compreender como a disciplina atua, interage e influi em suas vidas profissionais, e mostrando que os conceitos da administração de operações podem ser aplicados a outras disciplinas.
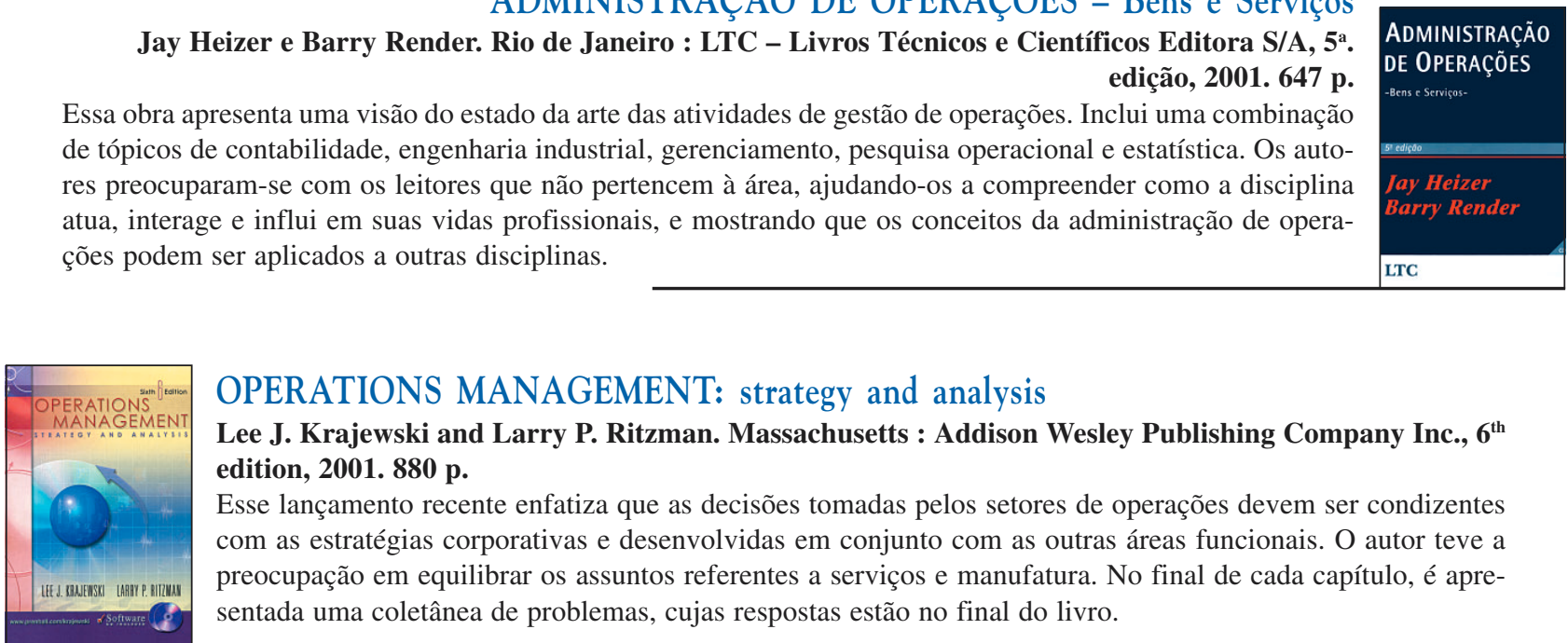

OPERATIONS MANAGEMENT: strategy and analysis

Lee J. Krajewski and Larry P. Ritzman. Massachusetts : Addison Wesley Publishing Company Inc., $6^{\text {th }}$ edition, 2001. 880 p.

Esse lançamento recente enfatiza que as decisões tomadas pelos setores de operações devem ser condizentes com as estratégias corporativas e desenvolvidas em conjunto com as outras áreas funcionais. $\mathrm{O}$ autor teve a preocupação em equilibrar os assuntos referentes a serviços e manufatura. No final de cada capítulo, é apresentada uma coletânea de problemas, cujas respostas estão no final do livro. 